\author{
UNIVERSIDADE DE SÃO PAULO \\ MUSEU DE ARQUEOLOGIA E ETNOLOGIA \\ PROGRAMA DE PÓS-GRADUAÇÃO EM ARQUEOLOGIA
}

\title{
ZOOARQUEOLOGIA DOS SÍTIOS ARQUEOLÓGICOS MARACAJU 1, MS E SANTA ELINA, MT
}

Mírian Liza Alves Forancelli Pacheco

Dissertação apresentada ao Programa de Pós-Graduação em Arqueologia do Museu de Arqueologia e Etnologia da Universidade de São Paulo para obtenção do título de Mestre em Arqueologia.

Orientador: Prof. Dr. Levy Figuti

Linha de Pesquisa: Processos de formação do registro arqueológico 
Mírian Liza Alves Forancelli Pacheco

\section{ZOOARQUEOLOGIA DOS SÍTIOS ARQUEOLÓGICOS \\ MARACAJU 1, MS E SANTA ELINA, MT}

Banca examinadora

Presidente da Banca:

Membros

São Paulo, dezembro de 2008 
"A excitação da caçada é, propriamente, nossa busca; não somos perdoados se a fazemos mal ou totalmente. Deixar de pegar a presa é outra questão. Nascemos para procurar a verdade; possui-la pertence a um poder maior."

Montaigne 


\section{Agradecimentos}

Manifesto meus sinceros agradecimentos às pessoas e às instituições que impulsionaram o início e o desenvolvimento deste trabalho. Agradeço:

Ao Prof. Dr. Levy Figuti (MAE/USP), por ter aceitado me orientar e pela orientação neste mestrado, pela confiança depositada, pelas etapas de campo, muito produtivas, em Joinville, por viabilizar meus estudos sobre a arqueofauna de Santa Elina e por sempre ter se demonstrado aberto às minhas idéias.

Aos Profs. Drs. Águeda Vilhena Vialou e Dennis Vialou (Museum National d'Histoire Naturelle, França) por permitirem que meu trabalho se tornasse parte das pesquisas do sítio arqueológico Santa Elina, MT. Serei eternamente grata ao entusiasmo, à disponibilidade e à paciência da Prof ${ }^{\mathrm{a}}$. Águeda, durante as minhas pesquisas.

Ao Museu de Arqueologia da Universidade de São Paulo, pela oportunidade de realizar este trabalho. Ao CNPq, pela bolsa de mestrado concedida. Ao IPHAN, pela licença por meio da qual foi possível desenvolver as campanhas de escavação em Maracaju, MS, em 2007. À TBG (Transportadora Brasileira do Gasoduto BolíviaBrasil), pelo apoio logístico na ocasião da confecção da coleção osteológica de referência do LPA/UFMS (2002/2007).

Ao Prof. Dr. Flávio de Barros Molina (Univ. Ibirapuera), pelo auxílio valioso e pelas discussões durante as pesquisas sobre a Ecologia e a Taxonomia dos Megalobulimidae.

Ao Prof. Dr. Marcelo Bordignon (CCBS/UFMS) pela preciosa ajuda, no processo de identificação taxonômica dos vestígios arqueofaunísticos, dos pequenos mamíferos resgatados em Santa Elina.

À Prof ${ }^{\mathrm{a}}$. Dr ${ }^{\mathrm{a}}$. Emília Mariko Kashimoto (LPA/MUARQ/UFMS), por ter me viabilizado os estudos sobre a arqueofauna resgatada nos sítios arqueológicos do Alto Paraná, pelo carinho e pela generosidade como me ensinou as técnicas de campo e laboratório, em Arqueologia, por nossas longas conversas durante as viagens em Mato Grosso do Sul.

Ao biólogo Marlos Sampaio (mestrando/ICB/USP), ao Msc. André Osório Rosa (Instituto Anchietano de Pesquisas) e ao Prof. Dr. Josué Raizer (CCBS/UFMS) por terem me auxiliado durante a compilação dos meus dados, em testes estatísticos. 
Ao Prof. Dr. Albérico N. de Queiroz (UFPE), pelo entusiasmo em viabilizar a divulgação das pesquisas zooarqueológicas, e me incluir no processo.

Aos Profs. Drs. Renato Kipnis (IB/USP) e Marisa Coutinho Afonso (MAE/USP) pelo auxílio, pelas sugestões, pelas discussões e pelas idéias durante o desenvolvimento deste trabalho.

Aos Profs. Drs. Renata Pardini, Luís Fábio Silveira e Ricardo Pinto da Rocha (IB/USP), por tudo o que me ensinaram sobre métodos de inventário em Zoologia (técnicas e conceitos que apliquei neste trabalho). Agradeço ao Prof. Dr. Luís Fábio Silveira pelos artigos disponibilizados sobre a ornitofauna do Cerrado e pelo auxílio durante os processos de identificação taxonômica e tafonomia da arqueofauna de Santa Elina.

À bióloga e amiga, Aurora Maria R. de Oliveira (CCBS/UFMS), por dispor de seu tempo e sua paciência, durante as etapas dos experimentos de diagênese no Cerrado, e por disponibilizar os resultados de sua pesquisa sobre sazonalidade dos frutos, do Pantanal e do Cerrado, para discussão nesta dissertação.

Aos amigos Luana Morais, Déborah Monteiro (biólogas) e Alessandro M. de Oliveira e Roberto Lopes Santos (acadêmicos/Ciências Biológicas/UFMS) pelo incansável apoio, durante os feriados, os finais de semana e as férias, na ocasião dos experimentos de diagênese, em campo e laboratório.

À arqueóloga e amiga, Ximena Villagran (IGC/USP) pelas sugestões de como trabalhar os resultados dos experimentos de diagênese.

Ao amigo João Cabral de Medeiros por ter me disponibilizado sua casa, seus livros e seu computador, e até, seus remédios, durante este mestrado.

À equipe do LPA/MUARQ/UFMS, pelo auxílio durante as etapas de campo e laboratório.

À amiga Marina Teixeira Figueiredo, pelo apoio, pela paciência e pela revisão do meu "abstract".

À Camila Constantino Alves (MAE/USP), pelo apoio e pela amizade incondicional. Por me convidar a fazer parte das suas pesquisas e das suas idéias, pelas caronas e pelas madrugadas de estudos compartilhadas.

À Paula Nishida, por ter sido, muitas vezes, conselheira, por me apoiar em minhas escolhas, pela paciência, e por ter lido as várias versões dos meus capítulos.

À Patrícia Fernanda Fischer (MAE/USP), pelo apoio, pela lealdade e por ter tornado meus pesados dias de trabalho em laboratório, mais leves. 
À Tatiane Sousa (MAE/USP), pela amizade verdadeira, pelas idéias que compartilhamos e por nossas risadas em campo e em laboratório.

À Daniela Klokler, por discutir minhas dúvidas e ler meus textos.

Ao Prof. Msc. Paulo Robson (DBI/UFMS), pelas fotos dos ossos sob o estereomicroscópio;

A Silvia H. Kawamoto, Alessandro M. de Oliveira (acadêmicos do curso de Ciências Biológicas/UFMS) e Lucicleide G. dos Santos (Turismóloga), durante as escavações no sítio Maracaju 1;

À Prof ${ }^{\mathrm{a}}$. Dr ${ }^{\mathrm{a}}$. Maria Rita Marques (chefe do Laboratório de Bioquímica/DBI/CCBS/UFMS) e à Msc. em Botânica Valdívia Rocha Morceli, pelo apoio científico e pela viabilização acadêmica para o desenvolvimento dos experimentos de diagênese, realizados no bioma do Cerrado;

A Rafael Brandi por ter disposto do seu tempo para confeccionar o mapa dos sítios do Planalto Maracaju - Campo Grande.

Ao amigo Eduardo Bespalez (MAE/USP), pela paciência, por ter me ensinado muito e pelas nossas discussões, em campo e em laboratório, sobre Arqueologia.

Aos estagiários Joana Faria, Tiago Atorre e Thiago Gramuglia (MAE/USP) pela amizade que desenvolvemos ao longo deste mestrado.

À amiga Maria Bernatede Póvoa e à Prof ${ }^{\mathrm{a}}$ Dr$^{\mathrm{a}}$. Marcia Angelina Alves (MAE/USP), pelo carinho quando me receberam em Aquidauana, em minha primeira escavação arqueológica. Também as agradeço pelo apoio e pelo interesse no andamento do meu trabalho.

Ao amigo Marcelo Fagundes, pela confiança, por nossas intermináveis conversas sobre Arqueologia e pela inspiração das suas idéias. O admiro como pessoa, amigo e pesquisador.

A Lúcia Monteiro e Liliana Piatti, amigas e biólogas responsáveis pelo levantamento faunístico na área do entorno do sítio Maracaju 1. Obrigada por terem transformado aquele trabalho tão ardoroso em momentos tão divertidos, únicos.

A Ulysses Amorim e Évellyn B. Ramos, meus dois grandes amigos da faculdade. À Anita, minha irmã. Obrigada por compartilharem dos meus sonhos, por apoiarem minhas decisões e por se fazerem sempre presentes nos momentos mais difíceis e nos mais alegres da minha vida. 
A Arkley Marques Bendeira (MAE/USP), amigo presente, leal, incondicional, generoso. Agradeço pelo apoio, pela paciência e por sempre ter me inserido nos seus trabalhos e nas suas oportunidades. Serei sempre grata por sua amizade.

Tentei fazer um agradecimento para cada uma, mas não consigo atribuir agradecimentos separados a vocês duas. Camila Aoki (PPG Biologia e Conservação/UFMS) e Regiane S. Ferreira (PPG Ecologia/INPA), minhas grandes amigas de juventude e da vida toda, dos sonhos e das expectativas. Este espaço é pequeno demais para sumarizar tudo o que elas representam pra mim. Obrigada por terem disposto do tempo, das férias e da coragem, sempre ao meu lado em minhas empreitadas. Amigas presentes, mesmo tão distantes. Obrigada pelas revisões e pelas discussões incansáveis, mas, principalmente, obrigada pelo colo.

Ao Prof. Dr. Gilson Rodolfo Martins (LPA/MUARQ/UFMS), meu mentor, por tudo o que me ensinou sobre ética, pesquisa, trabalho, credibilidade, rigor $\mathrm{e}$ perseverança. Devo a ele meus primeiros contatos com a Arqueologia, minhas primeiras escavações arqueológicas, minha bolsa de iniciação científica, minha inserção no meio acadêmico, minhas primeiras consultorias. Serei eternamente grata por seu entusiasmo frente às minhas idéias (quando este entusiasmo era merecido) e por sua prontidão em ensinar o certo, quando foi preciso. Acima de tudo, o agradeço pela confiança e pelo apoio às minhas escolhas.

Ao meu esposo, Elbio Leiguez Junior, companheiro leal nesta longa jornada, pelas noites em claro, imprimindo capítulos, conferindo tabelas, consertando impressora. Obrigada por me ouvir e por discutir comigo minhas idéias. Obrigada por tornar o meu trabalho, muitas vezes, o seu trabalho.

Aos meus pais, Ilza Alves Pacheco e Manuel Pacheco Junior, que trabalharam para que eu pudesse realizar os meus sonhos. Obrigada pelas noites mal dormidas, em função das minhas crises de asma, pelo financiamento paralelo às pesquisas, pelas expectativas, pela confiança e por terem me ensinado a querer e a ir atrás. 


\begin{tabular}{|c|c|}
\hline \multicolumn{2}{|l|}{ Sumário } \\
\hline Agradecimentos & 4 \\
\hline Lista de figuras & 11 \\
\hline Lista de tabelas & 12 \\
\hline Lista de gráficos & 13 \\
\hline Lista de anexos & 18 \\
\hline Abstract & 19 \\
\hline Resumo & 20 \\
\hline Introdução & 21 \\
\hline $\begin{array}{l}\text { Capítulo 1. Breve panorama das pesquisas arqueológicas realizadas no bioma de } \\
\text { Cerrado, em Mato Grosso e Mato Grosso do Sul }\end{array}$ & 23 \\
\hline $\begin{array}{l}\text { 1.1.A Arqueologia do bioma do Cerrado: Mato Grosso e Mato Grosso } \\
\text { do Sul }\end{array}$ & 23 \\
\hline 1.1.1. Caçadores-coletores & 23 \\
\hline ............1.1.2. Horticultores-ceramistas & 25 \\
\hline $\begin{array}{l}\text { Capítulo 2. A Ecologia e a Evolução aplicadas ao estudo do registro } \\
\text { arqueológico }\end{array}$ & 27 \\
\hline 2.1. Evolução: história, processo e teoria & 28 \\
\hline 2.2. O impacto do pensamento evolutivo na Arqueologia & 33 \\
\hline 2.2.1. Arqueologia evolutiva & 35 \\
\hline 2.2.2. Ecologia evolutiva & 40 \\
\hline $\begin{array}{l}\text { 2.2.2.1. Evolução e Ecologia: métodos divergentes, conceitos } \\
\text { complementares }\end{array}$ & 44 \\
\hline $\begin{array}{l}\text { Capítulo 3. A apropriação do ambiente por grupos humanos pretéritos: } \\
\text { mobilidade para a alocação de recursos alimentares }\end{array}$ & 48 \\
\hline 3.1. Cavernas e abrigos sob rocha $\mathrm{x}$ sítios a céu aberto & 48 \\
\hline 3.2. Mobilidade entre grupos humanos pretéritos & 49 \\
\hline 3.3. O modelo do forrageamento ótimo & 50 \\
\hline $\begin{array}{l}\text { 3.3.1. Modelos de subsistência humana aplicados ao estudo do } \\
\text { registro arqueológico }\end{array}$ & 53 \\
\hline $\begin{array}{l}\text { 3.3.2. As atividades de subsistência humana no gradiente } \\
\text { paisagístico do bioma do Cerrado }\end{array}$ & 58 \\
\hline $\begin{array}{l}\text { Capítulo } 4 \text {. Questões, hipóteses e objetivos: as pesquisas em Maracaju } 1 \text { e Santa } \\
\text { Elina sob a perspectiva zooarqueológica }\end{array}$ & 62 \\
\hline Capítulo 5. A interdisciplinaridade em Zooarqueologia & 68 \\
\hline 5.1. Zooarqueologia: definições, objetivos e métodos & 68 \\
\hline 5.2. Taxonomia e os sistemas de nomenclatura zoológica & 69 \\
\hline 5.2.1. Nomenclatura zoológica tradicional & 70 \\
\hline 5.2.2. Sistemática Filogenética ou Cladística & 70 \\
\hline $\begin{array}{l}\text { 5.3. A aplicabilidade das coleções osteológicas de referência em } \\
\text { estudos da fauna sub-recente }\end{array}$ & 72 \\
\hline 5.4. Ecologia e Biogeografia & 73 \\
\hline 5.4.1. Métodos de quantificação: Bioestatística e índices de diversidade & 74 \\
\hline 5.5. Zooarqueologia e Biologia da Conservação & 77 \\
\hline 5.6. Tafonomia & 78 \\
\hline 5.6.1. Tafonomia experimental & 80 \\
\hline
\end{tabular}


5.6.1.1. A estrutura do osso

5.6.1.2. Processos que levam à deterioração do tecido ósseo no registro arqueológico

5.6.1.3. Microrganismos decompositores

85

5.6.1.4. Mecanismos de degradação do tecido ósseo por microrganismos decompositores no solo

5.7. A Zooarqueologia e a História 92

5.8. A Zooarqueologia no Brasil

93

Capítulo 6. Panorama das pesquisas realizadas no sítio arqueológico Maracaju 1, Maracaju, MS

6.1. Caracterização ambiental da área do entorno do sítio arqueológico Maracaju 1

6.2. Campanhas arqueológicas

6.3. Datações e estratigrafia

Capítulo 7. Panorama das pesquisas realizadas no sítio arqueológico Santa Elina, Jangada, MT

7.1. Caracterização ambiental da área do entorno do sítio arqueológico

Santa Elina

7.2. Campanhas arqueológicas

114

7.3. Cronoestratigrafia

115

7.4. Panorama de ocupação em Santa Elina

Capítulo 8. Técnicas e métodos aplicados ao estudo da arqueofauna

120

8.1. Identificação anatômica/taxonômica

120

8.2. Quantificações

120

8.2.1. A quantificação da arqueofauna resgatada em Maracaju 1

120

8.2.2. A quantificação da arqueofauna resgatada em Santa Elina

8.3. Tafonomia

123

8.3.1. Tafonomia analítica

123

8.3.2. Tafonomia experimental

8.3.2.1. Experimento 1: efeitos macroscópicos da diagênese sobre ossos de vertebrados

8.3.2.2. Experimento 2: Tafonomia microbiológica

8.4. Compilação dos dados

125

Capítulo 9. Resultados

126

127

9.1. Sítio arqueológico Maracaju 1

127

9.1.1. Identificação anatômica/taxonômica

9.1.2. Quantificação da arqueofauna

128

9.2. Sítio arqueológico Santa Elina 136

9.2.1. Conjunto estratigráfico I 136

9.2.1.1. Características gerais de distribuição e quantificação da arqueofauna

9.2.1.2. Distribuição e quantificação dos vestígios

arqueoconquiliológicos

9.2.1.3. Distribuição e quantificação dos vestígios arqueomastofaunísticos

9.2.2. Conjunto estratigráfico II 


\begin{tabular}{|c|c|}
\hline $\begin{array}{l}\text { 9.2.2.1. Características gerais de distribuição e quantificação da } \\
\text { arqueofauna }\end{array}$ & 182 \\
\hline $\begin{array}{lllll}\text { 9.2.2.2. Distribuição } & \text { e } & \text { quantificação } & \text { dos } & \text { vestígios } \\
\text { arqueoconquiliológicos } & & & \end{array}$ & 189 \\
\hline 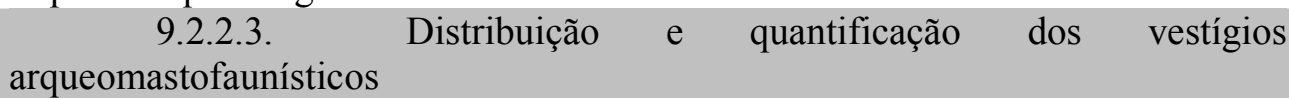 & 195 \\
\hline 9.2.3. Conjunto estratigráfico III & 203 \\
\hline 9.3. Tafonomia & 208 \\
\hline 9.3.1. Tafonomia experimental & 208 \\
\hline $\begin{array}{l}\text { 9.3.1.1. Experimento 1: efeitos macroscópicos da diagênese sobre } \\
\text { carcaças enterradas em um bioma de Cerrado }\end{array}$ & 208 \\
\hline $\begin{array}{l}\text { 9.3.1.2. Experimento 2: Tafonomia microbiológica sobre carcaças de } \\
\text { animais enterradas em um bioma de Cerrado }\end{array}$ & 211 \\
\hline 9.3.2. Tafonomia analítica & 213 \\
\hline Discussão & 214 \\
\hline Considerações finais & 244 \\
\hline Referências bibliográficas & 247 \\
\hline Anexos & 270 \\
\hline
\end{tabular}




\begin{tabular}{|c|c|}
\hline \multicolumn{2}{|l|}{ Lista de figuras } \\
\hline Figura 1. Estrutura dos recursos faunísticos nos bioma & 56 \\
\hline Figura 2. As subformações do Cerrado & 59 \\
\hline $\begin{array}{l}\text { Figura 3. Agrupamentos tradicionais (quadro) e hipótese sobre relações } \\
\text { filogenéticas (cladrograma) entre os vertebrados atuais }\end{array}$ & 72 \\
\hline Figura 4. Mapa geomorfológico do Planalto Basáltico & 96 \\
\hline Figura 5. Técnicas de levantamento faunístico & 97 \\
\hline Figura 6. Mapa da cobertura vegetal atual no Planalto Basáltico & 101 \\
\hline Figura 7. Petróglifos retratados no sítio abrigo Maracaju 1 & 102 \\
\hline Figura 8. Sítio arqueológico Maracaju 1 - levantamento planialtimétrico & 104 \\
\hline $\begin{array}{l}\text { Figura 9. Sítio arqueológico Maracaju } 1 \text { - plano de escavação geral e } \\
\text { distribuição da arqueofauna }\end{array}$ & 105 \\
\hline Figura 10. Sítio arqueológico Maracaju 1 - plano de escavação do setor III & 106 \\
\hline $\begin{array}{l}\text { Figura 11. Sítio arqueológico Maracaju } 1 \text { - visão da entrada do abrigo pelo setor } \\
\text { I }\end{array}$ & 106 \\
\hline $\begin{array}{l}\text { Figura 12. Sítio arqueológico Maracaju 1: evidenciação das manchas de fogueira } \\
\text { e dos vestígios arqueofaunísticos, no setor I }\end{array}$ & 107 \\
\hline $\begin{array}{l}\text { Figura 13. Sítio arqueológico Maracaju } 1 \text { - frutos carbonizados evidenciados em } \\
\text { uma das manchas de fogueira do setor I }\end{array}$ & 108 \\
\hline Figura 14. Sítio arqueológico Maracaju 1: perfil 1 & 109 \\
\hline Figura 15. Localização do sítio arqueológico Santa Elina & 112 \\
\hline Figura 16. Planta esquemática da área do entorno do abrigo de Santa Elina & 113 \\
\hline $\begin{array}{l}\text { Figura 17. Corte estratigráfico de Santa Elina, apresentando todos os níveis de } \\
\text { ocupações humanas }\end{array}$ & 114 \\
\hline Figura 18. Santa Elina: plano de escavação & 115 \\
\hline Figura 19. Santa Elina: corte estratigráfico $29 / 30$ oeste & 116 \\
\hline Figura 20. Ossos de papagaio semeados em placas com meio BDA & 126 \\
\hline Figura 21. Lamínulas aderidas ao microcultivo das culturas isoladas dos ossos & 126 \\
\hline Figura 22. vestígios resgatados na segunda campanha arqueológica & 127 \\
\hline $\begin{array}{l}\text { Figura 23. Sítios arqueológicos localizados no Planalto Basáltico Maracaju - } \\
\text { Campo Grande }\end{array}$ & 135 \\
\hline Figura 24 Santa Elina: Megalobolimus sp. com orifício em sua quinta volta & 142 \\
\hline Figura 25. Arqueofauna de Santa Elina & 155 \\
\hline Figura 26. Organização espacial de dois níveis recentes & 181 \\
\hline $\begin{array}{l}\text { Figura 27. Plano das combustões datadas entre } 9.000 \text { e } 10.000 \text { anos B.P., setor } \\
\text { leste }\end{array}$ & 186 \\
\hline $\begin{array}{l}\text { Figura 28. Distribuição horizontal dos vestígios arqueofaunísticos no conjunto } \\
\text { estratigráfico III }\end{array}$ & 205 \\
\hline $\begin{array}{l}\text { Figura 29. Duas escápulas do segundo mamífero resgatado: a esquerda não foi } \\
\text { submetida à fervura, a direita foi submetida à fervura (as setas indicam os } \\
\text { orifícios realizados pelos artrópodes do solo) }\end{array}$ & 210 \\
\hline $\begin{array}{l}\text { Figura } 30 . \text { Conídios e esporos de alguns fungos isolados dos ossos do } \\
\text { psitacídeo submetido à diagênese }\end{array}$ & 212 \\
\hline Figura 31. Assinaturas tafonômicas na arqueofauna & 213 \\
\hline
\end{tabular}




\begin{tabular}{|c|c|}
\hline Lista de tabelas & \\
\hline Tabela 1. Características do tecido ósseo & 84 \\
\hline $\begin{array}{l}\text { Tabela 2. Resultado do levantamento da herpetofauna do entorno do sítio } \\
\text { arqueológico }\end{array}$ & 98 \\
\hline $\begin{array}{l}\text { Tabela 3. Resultado do levantamento da ornitofauna e da mastofauna do } \\
\text { entorno do sítio arqueológico Maracaju } 1\end{array}$ & 99 \\
\hline Tabela 4. Maracaju 1: profundidade das camadas na quadrícula 19J & 110 \\
\hline Tabela 5. fauna avistada no entorno do abrigo de Santa Elina & 111 \\
\hline Tabela 6 : Santa Elina: tabela sintética das datações & 119 \\
\hline $\begin{array}{l}\text { Tabela 7. Santa Elina: distribuição das datações ao longo dos conjuntos } \\
\text { estratigráficos }\end{array}$ & 122 \\
\hline $\begin{array}{l}\text { Tabela 8. Santa Elina: distribuição das datações ao longo das camadas do } \\
\text { conjunto estratigráfico I }\end{array}$ & 122 \\
\hline Tabela 9. Arqueofauna resgatada no sítio arqueológico Maracaju 1 & 128 \\
\hline $\begin{array}{l}\text { Tabela 10. Maracaju 1: NISP, NMI e fragmentos não identificados de ossos de } \\
\text { mamíferos (NIM) }\end{array}$ & 128 \\
\hline Tabela 11. Número de fragmentos com ação térmica, NISP e NIM & 130 \\
\hline $\begin{array}{l}\text { Tabela 12. Maracaju 1, setor III: NISP, NMI e fragmentos não identificados de } \\
\text { ossos de mamíferos (NIM) }\end{array}$ & 131 \\
\hline Tabela 13. Arqueofauna resgatada no sítio arqueológico Santa Elina & 136 \\
\hline Tabela 14. Santa Elina: NMI para os gastrópodes resgatados no conjunto I & 142 \\
\hline Tabela 15. Santa Elina: NISP para os gastrópodes resgatados no conjunto I & 142 \\
\hline Tabela 16. Santa Elina: NISPAT para os gastrópodes resgatados no conjunto I & 142 \\
\hline $\begin{array}{l}\text { Tabela 17. Santa Elina: índices de riqueza e diversidade para o conjunto } \\
\text { estratigráfico I }\end{array}$ & 143 \\
\hline $\begin{array}{l}\text { Tabela 18. Santa Elina. Índices de riqueza e diversidade para a arqueofauna } \\
\text { resgatada no conjunto II }\end{array}$ & 190 \\
\hline $\begin{array}{l}\text { Tabela 19. Santa Elina. Índices de riqueza e diversidade para a } \\
\text { arqueomastofauna resgatada nos conjuntos estratigráficos I e II }\end{array}$ & 196 \\
\hline $\begin{array}{l}\text { Tabela } 20 \text {. Santa Elina. Índices de riqueza e diversidade para a arqueofauna } \\
\text { resgatada no conjunto III }\end{array}$ & 203 \\
\hline $\begin{array}{l}\text { Tabela 21. Santa Elina. Índices de riqueza e diversidade para a } \\
\text { arqueomastofauna resgatada no conjunto estratigráfico III }\end{array}$ & 206 \\
\hline $\begin{array}{l}\text { Tabela 22. Relação entre o NMI total e o número de quirópteros ao longo dos } \\
\text { conjuntos estratigráficos }\end{array}$ & 207 \\
\hline $\begin{array}{l}\text { Tabela } 23 \text {. Ossos do esqueleto de canário-da-terra recuperados na primeira } \\
\text { coleta }\end{array}$ & 209 \\
\hline Tabela 24. Assinaturas tafonômicas em ossos apendiculares de canário-da-terra & 209 \\
\hline $\begin{array}{l}\text { Tabela 25. Relação dos taxa micológicos identificados nos ossos do psitacídeo } \\
\text { enterrado no Cerrado, em } 2008\end{array}$ & 211 \\
\hline
\end{tabular}




\section{Lista de gráficos}

Gráfico 1. Quadro geral das datações para o conjunto estratigráfico I em Santa

Elina: z versus quadras no eixo longitudinal leste/oeste

Gráfico 1. Quadro geral das datações para o conjunto estratigráfico I em Santa

Elina: z versus quadras no eixo longitudinal leste/oeste

Gráfico 3. Maracaju 1: relação entre número de fragmentos e número de fragmentos com ação térmica

Gráfico 4. Maracaju 1, setor III: distribuição de NISP e NMI por camada

Gráfico 5. Maracaju 1, setor III: NMI versus NISP por camada

Gráfico 6. Maracaju 1, setor III: porcentagem de fragmentos ósseos com ação do fogo por camada

Gráfico 7. Santa Elina: índices de quantificação para os grupos monofiléticos resgatados na camada superficial

Gráfico 8. Santa Elina: índices de quantificação para os grupos monofiléticos resgatados na camada I

Gráfico 9. Santa Elina: índices de quantificação para os grupos monofiléticos resgatados na camada II

Gráfico 10. Santa Elina: índices de quantificação para os grupos monofiléticos resgatados na camada III

Gráfico 11. Santa Elina: índices de quantificação para os grupos monofiléticos

resgatados na camada IV

Gráfico 12. Santa Elina: índices de quantificação para os grupos monofiléticos resgatados na camada $\mathrm{V}$

Gráfico 13. Santa Elina: índices de quantificação para os grupos monofiléticos resgatados na camada VI

Gráfico 14. Santa Elina: ocorrência dos vestígios arqueoconquiliológicos de Megalobulimus sp. através das profundidades (eixo longitudinal - setor leste) no conjunto estratigráfico I

Gráfico 15. Santa Elina: ocorrência dos vestígios arqueoconquiliológicos de Megalobulimus sp., com ação térmica através das profundidades no conjunto estratigráfico I (eixo longitudinal - setor leste)

Gráfico 16. Santa Elina: ocorrência dos vestígios arqueoconquiliológicos de Megalobulimus sp. através das profundidades no conjunto estratigráfico I (eixo transversal - setor leste)

Gráfico 17. Santa Elina: ocorrência dos vestígios arqueoconquiliológicos de Megalobulimus sp. com ação térmica através das profundidades no conjunto estratigráfico I (eixo transversal - setor leste)

Gráfico 18. Santa Elina: distribuição dos valores de NISP para os vestígios arqueoconquiliológicos de Megalobulimus sp. ao longo das profundidades no conjunto estratigráfico I (setor leste)

Gráfico 19. Santa Elina: distribuição dos valores de NISPAT para os vestígios arqueoconquiliológicos de Megalobulimus sp. ao longo das profundidades (setor leste)

Gráfico 20. Santa Elina: ocorrência dos vestígios arqueoconquiliológicos de Megalobulimus sp. através das profundidades conjunto estratigráfico I (eixo longitudinal - setor oeste)

Gráfico 21. Santa Elina: ocorrência dos vestígios arqueoconquiliológicos de Megalobulimus sp., com ação térmica, através das profundidades no conjunto estratigráfico I (eixo longitudinal - setor oeste)

Gráfico 22. Santa Elina: ocorrência dos vestígios arqueoconquiliológicos de 
Megalobulimus sp. através das profundidades no conjunto estratigráfico I (eixo transversal - setor oeste)

Gráfico 23. Santa Elina: ocorrência dos vestígios arqueoconquiliológicos de Megalobulimus sp., com ação térmica. através das profundidades no conjunto estratigráfico I (eixo transversal - setor oeste)

Gráfico 24. Santa Elina: distribuição dos valores de NISP para os vestígios arqueoconquiliológicos de Megalobulimus sp. ao longo das profundidades no conjunto estratigráfico I (setor oeste)

Gráfico 25. Santa Elina: distribuição dos valores de NISPAT para os vestígios arqueoconquiliológicos de Megalobulimus sp. ao longo das profundidades no conjunto estratigráfico I (setor oeste)

Gráfico 26. Santa Elina: relações entre os índices de quatificação para os taxa de mamíferos resgatados na camada superficial

Gráfico 27. Santa Elina: relações entre os índices de quatificação para os taxa de mamíferos resgatados na camada I

Gráfico 28. Santa Elina: relações entre os índices de quatificação para os taxa de mamíferos resgatados na camada II

Gráfico 29. Santa Elina: relações entre os índices de quatificação para os taxa de mamíferos resgatados na camada III

Gráfico 30. Santa Elina: relações entre os índices de quatificação para os taxa de mamíferos resgatados na camada IV

Gráfico 31. Santa Elina: relações entre os índices de quatificação para os taxa de mamíferos resgatados na camada $\mathrm{V}$

Gráfico 32. Santa Elina: relações entre os índices de quatificação para os taxa de mamíferos resgatados na camada VI

Gráfico 33. Santa Elina: valores dos índices de quantificação das classes de tamanho dos mamíferos resgatados na camada superficial

Gráfico 34. Santa Elina: valores dos índices de quantificação das classes de tamanho dos mamíferos resgatados na camada I

Gráfico 35. Santa Elina: valores dos índices de quantificação das classes de tamanho dos mamíferos resgatados na camada II

Gráfico 36. Santa Elina: valores dos índices de quantificação das classes de tamanho dos mamíferos resgatados na camada III

Gráfico 37. Santa Elina: valores dos índices de quantificação das classes de tamanho dos mamíferos resgatados na camada IV

Gráfico 38. Santa Elina: valores dos índices de quantificação das classes de tamanho dos mamíferos resgatados na camada $\mathrm{V}$

Gráfico 39. Santa Elina: índices de quantificação x porte dos mamíferos na camada VI

Gráfico 40. Santa Elina: variação do NMI entre as classes de tamanho dos mamíferos nas camadas do conjunto estratigráfico I

Gráfico 41. Santa Elina: variação dos NISP entre as classes de tamanho dos mamíferos nas camadas do conjunto estratigráfico I

Gráfico 42. Santa Elina: variação do NISPAT entre as classes de tamanho dos mamíferos nas camadas do conjunto estratigráfico I

Gráfico 43. Santa Elina: relações entre as médias de NMI para as diferentes classes de tamanho através das camadas, no conjunto estratigráfico I Gráfico 44. Santa Elina: relações entre as médias de NISP para as diferentes classes de tamanho através das camadas, no conjunto estratigráfico I Gráfico 45. Santa Elina: relações entre as médias de NISPAT para as diferentes 
classes de tamanho através das camadas, no conjunto estratigráfico I

Gráfico 46. Santa Elina: relação entre os valores totais dos índices de quantificação e as classes de tamanho da assembléia arqueofaunística resgatada no conjunto estratigráfico I

Gráfico 47. Santa Elina: valores de NISP para as partes anatômicas dos pequenos roedores nas camadas do conjunto estratigráfico I

Gráfico 48. Santa Elina: valores de NISPAT para as partes anatômicas dos pequenos roedores nas camadas do conjunto estratigráfico I

Gráfico 49. Santa Elina: ocorrência dos vestígios ósseos dos pequenos roedores através das profundidades no conjunto estratigráfico I (eixo longitudinal - setor leste)

Gráfico 50. Santa Elina: ocorrência dos vestígios ósseos dos pequenos roedores, com ação térmica, através das profundidades no conjunto estratigráfico I (eixo longitudinal - setor leste)

Gráfico 51. Santa Elina: ocorrência dos vestígios ósseos dos pequenos roedores através das profundidades no conjunto estratigráfico I (eixo transversal - setor leste)

Gráfico 52. Santa Elina: ocorrência dos vestígios ósseos dos pequenos roedores, com ação térmica, através das profundidades no conjunto estratigráfico I (eixo transversal - setor leste)

Gráfico 53. Santa Elina: distribuição dos valores de NISP para os vestígios ósseos dos pequenos roedores ao longo das profundidades no conjunto estratigráfico I (setor leste)

Gráfico 54. Santa Elina: distribuição dos valores de NISP para os vestígios ósseos dos pequenos roedores, com ação térmica, ao longo das profundidades no conjunto estratigráfico I (setor leste)

Gráfico 55. Santa Elina: ocorrência dos vestígios ósseos dos pequenos roedores através das profundidades no conjunto estratigráfico I (eixo longitudinal - setor oeste)

Gráfico 56. Santa Elina: ocorrência dos vestígios ósseos dos pequenos roedores, com ação térmica, através das profundidades no conjunto estratigráfico I (eixo longitudinal - setor oeste)

Gráfico 57. Santa Elina: ocorrência dos vestígios ósseos dos pequenos roedores através das profundidades no conjunto estratigráfico I (eixo transversal - setor oeste)

Gráfico 58. Santa Elina: ocorrência dos vestígios ósseos dos pequenos roedores, com ação térmica, através das profundidades (eixo transversal - setor oeste)

Gráfico 59. Santa Elina: distribuição dos valores de NISP para os vestígios ósseos dos pequenos roedores ao longo das profundidades no conjunto estratigráfico I (setor oeste)

Gráfico 60. Santa Elina: distribuição dos valores de NISPAT para os vestígios ósseos dos pequenos roedores ao longo das profundidades no conjunto estratigráfico I (setor oeste)

Gráfico 61. Santa Elina: concentração e dispersão dos vestígios faunísticos no conjunto estratigráfico II

Gráfico 62. Santa Elina: distribuição dos vestígios arqueofaunísticos no conjunto estratigráfico II

Gráfico 63. Santa Elina: distribuição dos vestígios arqueofaunísticos com ação térmica no conjunto estratigráfico II

Gráfico 64. Santa Elina: distribuição dos vestígios arqueofaunísticos (NISP) no 
conjunto estratigráfico II

Gráfico 65. Santa Elina: distribuição dos vestígios arqueofaunísticos com ação térmica (NISPAT) no conjunto estratigráfico II

Gráfico 66. Santa Elina: distribuição dos n. de fragmentos (NISP) através das profundidades no conjunto estratigráfico II

Gráfico 67. Santa Elina: distribuição dos n. de fragementos com ação térmica

(NISPAT) através das profundidades no conjunto estratigráfico II

Gráfico 68. Santa Elina: índices de quantificação para os grupos monofiléticos resgatados no conjunto estratigráfico II

Gráfico 69. Santa Elina: índices de quantificação para os gastrópodes resgatados no conjunto estratigráfico II

Gráfico 70. Santa Elina: ocorrência dos vestígios arqueoconquiliológicos de Megalobulimus sp. através das profundidades (eixo longitudinal - setor leste) no conjunto estratigráfico II

Gráfico 71. Santa Elina: ocorrência dos vestígios arqueoconquiliológicos de Megalobulimus sp., com ação térmica através das profundidades (eixo longitudinal - setor leste) no conjunto estratigráfico II

Gráfico 72. Santa Elina: distribuição dos valores de NISP para os vestígios arqueoconquiliológicos de Megalobulimus sp. ao longo das profundidades (eixo transversal- setor leste) no conjunto estratigráfico II

Gráfico 73. Santa Elina: distribuição dos valores de NISPAT para os vestígios arqueoconquiliológicos de Megalobulimus sp. ao longo das profundidades (eixo transversal- setor leste) no conjunto estratigráfico II

Gráfico 74. Santa Elina: distribuição dos valores de NISP para os vestígios arqueoconquiliológicos de Megalobulimus sp. ao longo das profundidades (eixo longitudinal - setor leste) no conjunto estratigráfico II

Gráfico 75. Santa Elina: distribuição dos valores de NISPAT para os vestígios arqueoconquiliológicos de Megalobulimus sp. ao longo das profundidades (eixo longitudinal - setor leste) no conjunto estratigráfico II

Gráfico 76. Santa Elina: relações entre os índices de quantificação para os taxa de mamíferos resgatados no conjunto estratigráfico II

Gráfico 77. Santa Elina: índices de quantificação x porte dos mamíferos no conjunto estratigráfico II

Grafico 78. Santa Elina: relação e distribuição entre os índices de quantificação (NISP e NISPAT) para as partes anatômicas dos pequenos roedores, resgatadas no conjunto estratigráfico II

Gráfico 79. Santa Elina: ocorrência dos vestígios ósseos dos pequenos roedores através das profundidades (eixo longitudinal - setor leste) no conjunto estratigráfico II

Gráfico 80. Santa Elina: ocorrência dos vestígios ósseos dos pequenos roedores, com ação térmica, através das profundidades (eixo longitudinal - setor leste) no conjunto estratigráfico II

Gráfico 81. Santa Elina: distribuição dos valores de NISP para os vestígios ósseos dos pequenos roedores ao longo das profundidades (eixo transversalsetor leste) no conjunto estratigráfico II

Gráfico 82. Santa Elina: distribuição dos valores de NISP para os vestígios ósseos dos pequenos roedores ao longo das profundidades (eixo transversalsetor leste) no conjunto estratigráfico II 
conjunto estratigráfico II

Gráfico 84. Santa Elina: distribuição dos valores de NISPAT para os vestígios

dos pequenos roedores, com ação térmica, ao longo das profundidades (eixo

longitudinal - setor leste) no conjunto estratigráfico II

202

Gráfico 85. Santa Elina: distribuição dos valores de NMI ao longo dos conjuntos

estratigráficos

203

Gráfico 86. Santa Elina: distribuição dos taxa no conjunto estratigráfico III

204

Gráfico 87. Santa Elina: conjunto estratigráfico III - NISP x NMI

206

Gráfico 88. Santa Elina: relações entre as médias de NMI para os taxa nos conjuntos estratigráficos I, II e III 


\section{Lista de anexos}

Anexo 1: portaria/IPHAN

Anexo 2: vestígios arqueofaunísticos descontextualizados

Anexo 3: datações de santa Elina

Anexo 4: protocolo de análise para a arqueofauna

Anexo 5: tabelas de dados brutos para a arqueofauna de Santa Elina

Anexo 6: Santa Elina - profundidades e decapagens 


\begin{abstract}
Archaeofaunistic remains rescued in archaeological sites from Mato Grosso and Mato Grosso do Sul have shown the existence of generalists past hunter-gatherers groups in these states. Embedded in this context, there are the archaeological sites Maracaju 1, MS and Santa Elina, MT, characterized by being rock shelters, with rock art, and a quantity of archaeofaunistic remains, along with other traces of material culture. Facing the above, this work aimed to (1) understand, from the perspective of archaeofauna, the subsistence patterns of the people who occupied Maracaju 1, and Santa Elina, two shelters in the Cerrado biome, (2) outlining the activities (specific or not) done by human groups who occupied these shelters, and face it, (3) deduce the function of these shelters for local people. To reach that, these zooarchaeological records were studied using multidisciplinary methods and techniques (e.g. Taxonomy and Experimental taphonomy). Facing these results, it was possible to infer that hunting and subsistence activities, in occupations attributed to hunters-gatherers in Maracaju 1, occurred in successive and probably seasonal context. This occupation characteristic has strengthened the hypothesis of the high degree of mobility and more horizontalised occupations in the landscape, characteristic of these human groups. Similarly, the most parsimonious explanation for the zooarchaeological context of Santa Elina, is that the human occupation, probably had a seasonal character and occurred during the resources allocation related to other cultural events, evidenced by the rock art and the archaeological remains rescued in this site.
\end{abstract}

Key words: Zooarcheology of MS, Zooarcheology of MT, archaeological site Maracaju 1, archaeological site Santa Elina 
Resumo. Vestígios arqueofaunísticos resgatados em sítios arqueológicos de Mato Grosso e Mato Grosso do Sul revelaram a existência pretérita de grupos humanos caçadores-coletores generalistas, nestes Estados. Inseridos neste contexto, estão os sítios arqueológicos Maracaju 1, MS e Santa Elina, MT, caracterizados por serem abrigos sob rocha, que apresentam painéis com inscrições rupestres, e por uma quantidade de remanescentes arqueofaunísticos, associados a outros vestígios da cultura material. Diante do exposto, o presente trabalho teve por objetivos (1) compreender, sob a perspectiva da arqueofauna, os padrões de subsistência das populações humanas pretéritas que ocuparam Maracaju 1, MS e Santa Elina, MT, dois abrigos em bioma de Cerrado; (2) delinear as atividades (específicas ou não) realizadas pelos grupos humanos que ocuparam estes abrigos; e, diante disso, (3) inferir a função destes abrigos para as populações pretéritas locais. Para tanto, estes registros zooarqueológicos foram estudados por meio de métodos e técnicas multidisciplinares (e.g. Taxonomia e Tafonomia experimental). Diante dos resultados deste trabalho, foi possível inferir que a caça e as atividades de subsistência, nas ocupações atribuídas aos caçadores-coletores, em Maracaju 1, ocorreram de modo sucessivo e, provavelmente, sazonal. Esta característica de ocupação fortaleceu a hipótese do elevado grau de mobilidade e das ocupações mais horizontalizadas na paisagem, característica desses grupos humanos. Do mesmo modo, a explicação mais parcimoniosa para o contexto zooarqueológico de Santa Elina, é a de que as ocupações humanas tiveram um caráter, provavelmente sazonal e ocorreram durante as alocações de recursos ligadas a outros eventos culturais, evidenciados pelos registros rupestres e pelos vestígios arqueológicos resgatados neste sítio.

Palavras-chave: Zooarqueologia de MS, Zooarqueologia de MT, sítio arqueológico Maracaju 1, sítio arqueológico Santa Elina 